\title{
PERFORMANCE OF A SOLAR PAPER DRIER FOR SMALL-SCALE PAPER SHEET PRODUCTION
}

\author{
Mikael Hjort ${ }^{1,2}$ and Daniel E. Thomas ${ }^{1,3, *}$ \\ ${ }^{1}$ Appropriate Technology Research Center, MCC Bangladesh, Dhaka, Bangladesh. \\ ${ }^{2}$ Current affiliation: ABB AB, Power Systems HVDC, Ludvika, Sweden. \\ ${ }^{3}$ Current affiliation: Department of Mechanical Engineering, University of Minnesota, USA. \\ "Corresponding e-mail: dthomas@umn.edu
}

\begin{abstract}
This study was conducted to evaluate the performance of a paper drier operating on solar-heated hot water. A small-scale prototype of a flat tank paper drier was built and tested in a variety of conditions and with a variety of handmade paper types. The tests showed consistent performance, with a specific energy consumption of about $3.5 \mathrm{MJ}$ per $\mathrm{kg}$ of water evaporated from the paper. This corresponds to a drier efficiency of up to $80 \%$, with reference to the latent heat of evaporation. Drier temperature variations were minimal, and the performance was considered satisfactory to continue with further development of the drier for local handmade paper production facilities. Measured drying rates compared well with predicted values calculated using correlations based on Stefan's law.
\end{abstract}

Keywords: paper drying, solar heating, drying efficiency, handmade paper.

\section{INTRODUCTION}

Small-scale paper manufacturing is widespread across South Asia. It is a local industry with a positive environmental impact, using waste fiber materials to produce paper and card stock with minimal waste and water consumption. ${ }^{1,2}$ Most of Bangladesh's paper production is low-grade card stock for local use, but the Mennonite Central Committee Bangladesh (MCCB) has developed high quality handmade paper for the export market, beginning in the early 1980s. There are now several handmade paper enterprises producing paper and paper products from waste jute and cotton, as well as other agricultural wastes: water hyacinth, pineapple leaves, and wheat straw.

Locally produced card stock is usually dried by laying sheets on the ground, in the sun. But direct solar drying is often not suitable for higher quality paper production, for several reasons: (1) sun-dried paper is more prone to be soiled and made defective, (2) paper that dries slowly tends to warp and wrinkle more, and (3) production must continue on days when there is little direct sunlight. The handmade paper facilities currently use gas or wood-fired driers, but these are expensive to operate. Indirect solar-heated driers have been examined as a costsaving and environmentally friendly alternative to these combustion-heated driers. This paper presents the results of the first step in this investigation, a small-scale prototype solar drier.

\section{EXPERIMENTAL METHOD}

The basic solar drier proposed consists of a closed loop system using water as the heat transfer medium, with a drier plate and solar water heater in series (Fig. 1). The drier plate is a flat steel tank, with interior channels to direct water back and forth in a zigzag flow pattern. The prototype was sized at $90 \mathrm{x}$ $60 \times 5 \mathrm{~cm}$ - for a single sheet of handmade paper which is laid up on the front; the back side is insulated and used for temperature measurements.

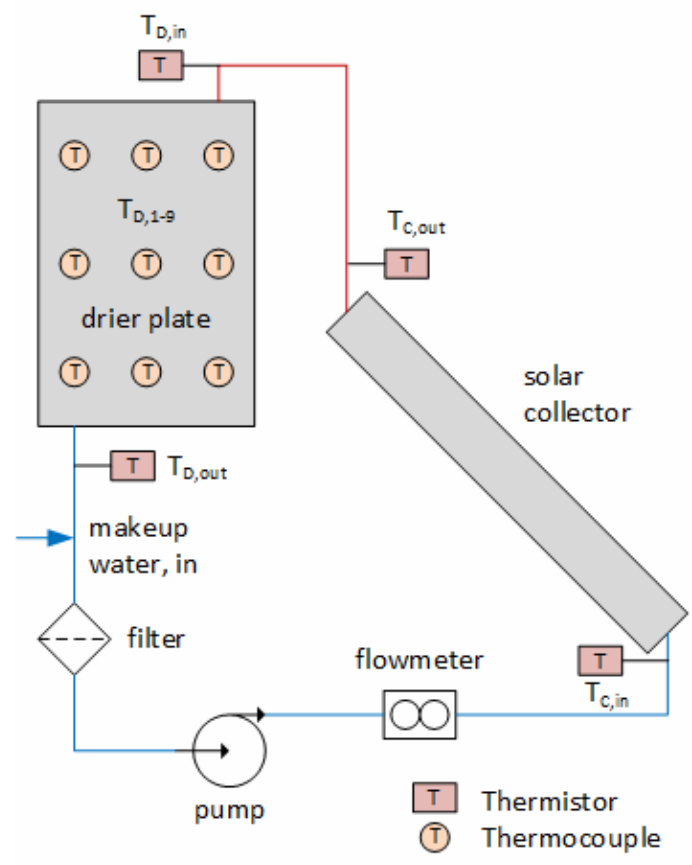

Figure 1. System layout, showing temperature measurement locations.

The solar collector used for the study is of the vacuum insulated glass tube variety, with 50 tubes arranged on both sides of a central manifold ('Htype', as shown in Fig. 2). The evacuated tube solar collectors of this type are widely used in large scale solar thermal installations in China, and are recently available in Bangladesh. ${ }^{3}$ With low heat losses, they 
allow higher efficiencies at water temperatures of 70$100^{\circ} \mathrm{C}$ than do traditional flat panel collectors. ${ }^{4,5}$ Some data was also taken using a $2000 \mathrm{~W}$ electric water heater in place of the solar collector. The performance of the collector itself will be evaluated and published separately; this study focuses on the performance of the drier.

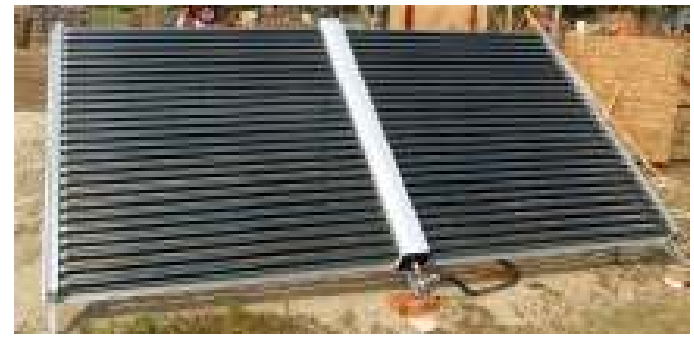

Figure 2. Evacuated tube solar collector used with the paper drier.

\section{INSTRUMENTATION}

Working fluid temperature measurements were made with precision thermistor probes $\left( \pm 0.1^{\circ} \mathrm{C}\right)$ at the points indicated in Fig. 1. Drier plate temperatures, $\mathrm{T}_{\mathrm{D}, 1-9}$, were measured with fine-wire type $\mathrm{T}$ thermocouples (calibrated for $\pm 0.5^{\circ} \mathrm{C}$ accuracy). These thermocouples were evenly spaced on the rear surface of the drier in the positions shown in Fig. 1, and covered with a sheet of foam insulation. Heat losses through the insulation are small, and this surface was assumed to be adiabatic. The average drier plate temperature was calculated as the average of the 9 thermocouple readings.

Solar radiation was measured with an Apogee SP212 pyranometer $( \pm 1 \%$ repeatability, $\pm 5 \%$ absolute accuracy). A shaded strip pyranometer, also using an SP-212, was used to measure diffuse radiation. Flow was measured with a Gems FT-330 Hall Effect turbine flow meter (listed at $\pm 2 \%$ accuracy, but calibrated for $\pm 1 \%$ ). All data was sampled at 5 second intervals, then averaged and recorded at 1 minute intervals with a Campbell Scientific CR10X datalogger ( $\pm 0.05 \%$ of full scale range).

\section{PROCEDURE}

After allowing water in the collector to heat up, the pump was turned on to circulate water and heat the drier plate. A variety of paper types and thicknesses were dried at different drier plate temperatures. For the purposes of this study, previously made dry paper was wet to a water content approximating that of the production situation. After recording the wet weight, the sheet was laid up on the drier using the method currently in use with existing driers: pressing it to the surface using a hand roller and lining the edges with a small amount of local arrarut gum (Fig. 3). The paper weight before and after drying, and drying time was recorded manually, all other data was recorded by the datalogger.

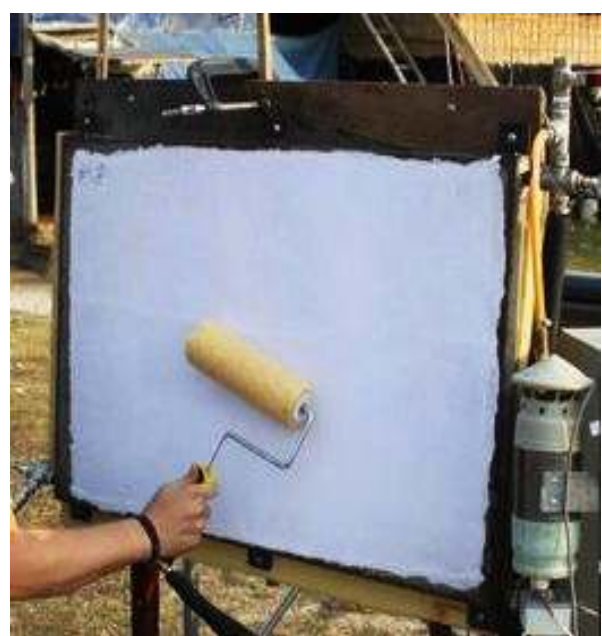

Figure 3. Wet handmade cotton paper sheet being applied to the drier surface with a roller.

\section{ANALYSIS and RESULTS}

The drying energy was taken as the energy removed from the working fluid, thereby including minor heat losses from the drier. This energy was calculated using the specific heat of water over the drying period:

$$
Q_{\text {out }}=\int_{0}^{t} \dot{m} c_{p}\left(T_{D, \text { out }}-T_{\text {Din }}\right) d t
$$

Where $m$ is the mass flow rate, and $\left(T_{D, \text { out }}-T_{D \text {,in }}\right)$ the temperature drop across the drier. The following are the main results from the data analysis:

1. Paper drying time is a function of the paper water content and dryer temperature, and is not significantly affected by fiber type. The results shown in Fig. 4 are normalized by the mass of water in the paper (to give units of minutes per $\mathrm{kg}$ water evaporated on the y axis), to account for variations in paper thickness and initial wetting. So for a typical thick cotton paper sheet containing $0.27 \mathrm{~kg}$ water, the drying time was $17 \mathrm{~min}$ at $70^{\circ} \mathrm{C}$. Two data sets were recorded for each fiber type: set 1 was taken indoors using an electric water heater as heat source, and set 2 was taken outside, using the solar collector as heat source. (Ambient conditions were similar for both data sets.)

2. The specific energy consumption for drying, shown in Fig. 5 is approximately $3.5 \mathrm{MJ} / \mathrm{kg}$ of water evaporated. It does not vary greatly with paper type or drier surface temperature. As expected there is more variation at lower plate temperatures, and less variation at the higher temperatures that would be used in a production setting.

Considering the performance at $70^{\circ} \mathrm{C}$, the measured specific energy consumption of $3.4 \mathrm{MJ} / \mathrm{kg}$ can be compared to the latent heat of vaporization at that temperature, plus the energy required to raise the evaporated water from ambient to $70^{\circ} \mathrm{C}$, giving an efficiency of $75 \%$. These corresponding efficiency 
values for the drying energy consumption above are shown in Fig. 6. Efficiency values approach $80 \%$ for the higher drier temperatures.

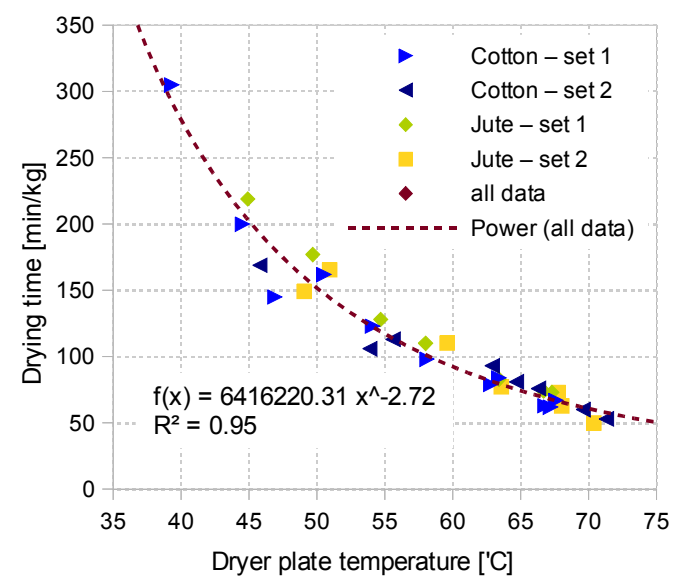

Figure 4. Drying time as a function of plate temperature for jute and cotton paper.

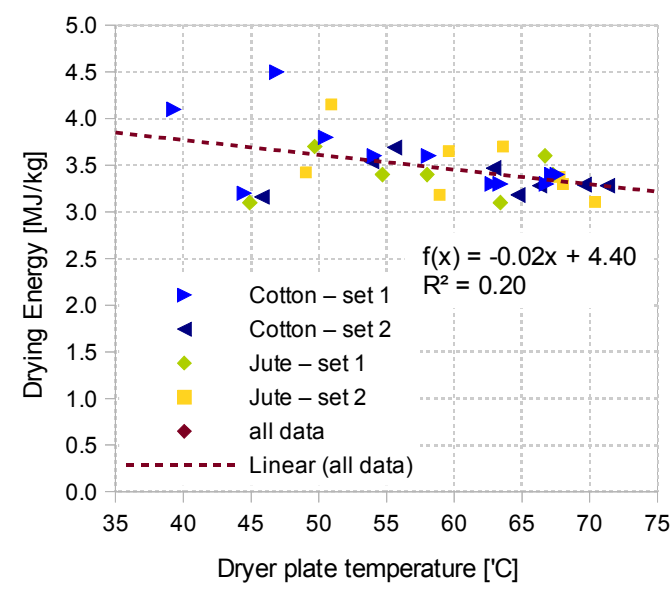

Figure 5. Variation of drier energy consumption with drier plate temperature.

3. With the internal drier channels oriented horizontally, the drier surface temperature distribution was minor, most of the surface falling within a $2^{\circ} \mathrm{C}$ range. The interior channels were initially oriented vertically, but the spatial temperature variations in this orientation were much greater. It was evident that all the flow was not following the intended path, but was leaking between channels. When the dryer was turned to the horizontal orientation, this leakage seemed to be minimal.

The drier surface temperatures, $\mathrm{T}_{\mathrm{D}, 1-9}$, are shown in Fig. 7 for a typical 2-hour period. The time period is 4:00 - 6:00 p.m., and shows a gradually decreasing surface temperature as the solar heat input decreases in the late afternoon. The other shorter time constant variations are the drop in temperature following the application of a new wet sheet of paper. This variation is also only on the order of $2^{\circ} \mathrm{C}$. It could of course be reduced by increasing the tank thickness and thermal mass of the drier, but the variation shown was not considered problematic.

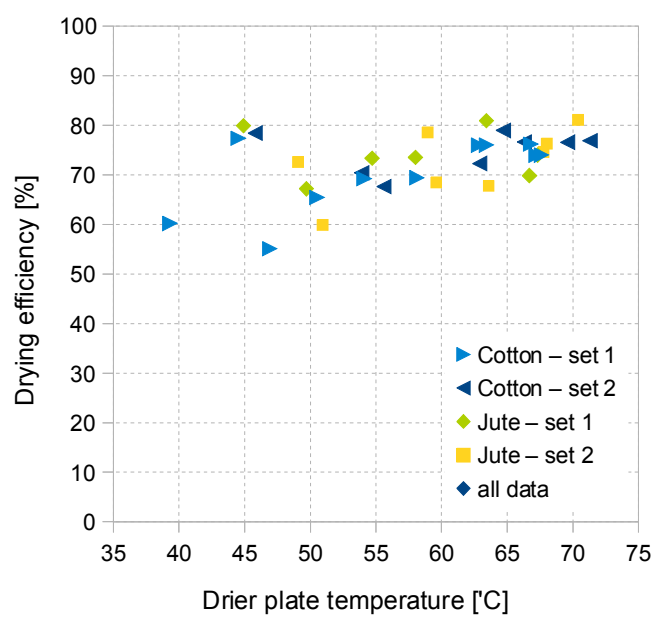

Figure 6. Drying efficiency with reference to energy required to heat up from ambient temperature and latent heat of vaporization.

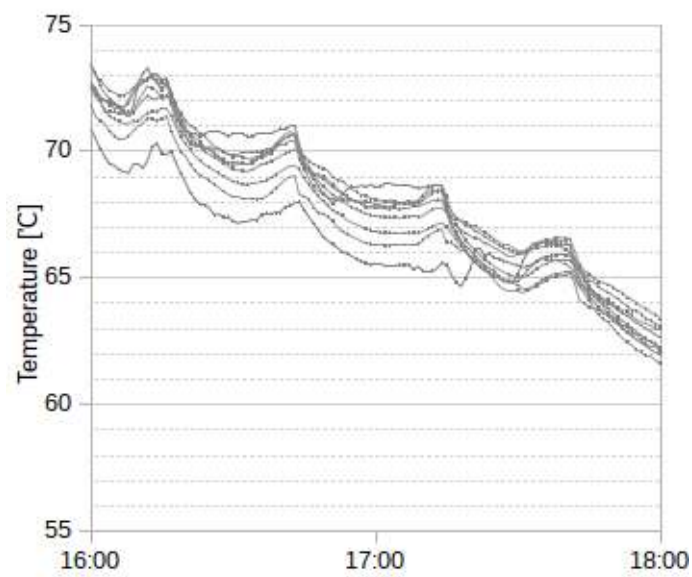

Figure 7. Drier plate surface temperature variation during operation: lines show the 9 surface temperature measurement points $\mathrm{T}_{\mathrm{D}, 1-9}$.

\section{Drying rate calculations}

In order to predict the drying rate from drier plate temperature and ambient air conditions, the energy balance method proposed by Ek, et al. was employed. ${ }^{6}$ The rate of mass transfer from the wet paper surface is given by Stefan's law:

$$
m_{\text {evap }}=\frac{k_{g} M_{w} P}{R\left(T_{p}+273\right)} \ln \left[\frac{P-p_{\text {air }}}{P-p_{p}}\right]
$$

The mass transfer coefficient $\mathrm{k}_{\mathrm{g}}$ is calculated from the heat transfer coefficient based on the heat and mass transfer analogy:

$$
k_{g}=\frac{h_{a i r}}{\rho c_{p}}
$$


The heat transfer coefficient is calculated using the Nusselt number correlation for free convection from a vertical isothermal plane proposed by Churchill and $\mathrm{Chu}^{7}$ (valid for the Rayleigh number range $10^{-1}<\mathrm{Ra}_{\mathrm{L}}<10^{12}$ ):

$$
\overline{N u}^{1 / 2}=0.825+\frac{0.387 R a^{1 / 6}}{\left[1+(0.492 / P r)^{9 / 16}\right]^{8 / 27}}
$$

The partial pressures of the air $p_{\text {air }}$ and paper $p_{p}$ are calculated with the equations provided provided by Ek, et al.:

$$
\begin{aligned}
& p_{\text {air }}=\frac{X}{(18 / 29)+X} P \\
& p_{p}=133.322 e^{\left(18.3036-\frac{3816.44}{T_{p}+227.02}\right)}
\end{aligned}
$$

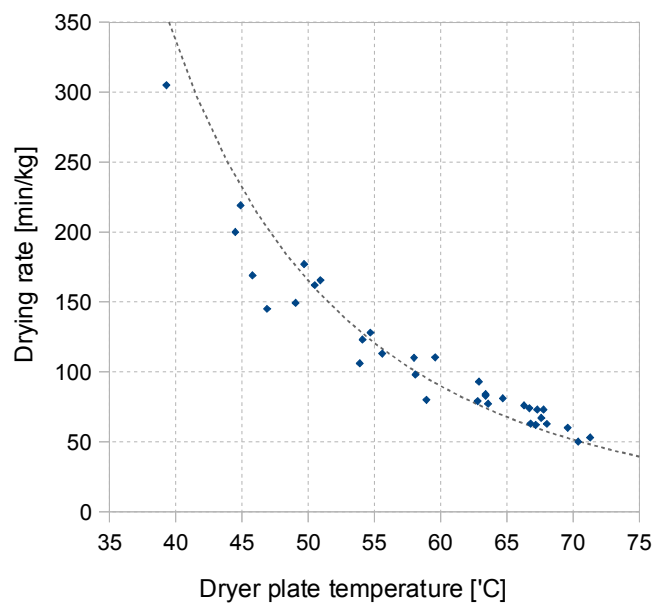

Figure 8. Predicted drying rate based on average ambient conditions, shown with measured results.

Thus the rate of evaporation from the drying paper is a function of only the paper temperature and ambient conditions. The temperature drop from the plate to the paper surface is calculated using a contact heat transfer coefficient, yielding temperature drops on the order of $2-7^{\circ} \mathrm{C}$, for the drier plate temperatures considered.

This method was used to satisfactorily predict drying rates, with results typically within $\pm 15 \%$ of measured values. As an example, Fig. 8 shows the predicted drying rates for the average ambient conditions of $27^{\circ} \mathrm{C}$ and $50 \%$ relative humidity. The predictions agree well with measured values, despite the fact that the actual ambient conditions at each data point deviate from the average values.

\section{CONCLUSIONS}

The drier tests gave results that could be satisfactorily correlated to a single parameter - the paper moisture content - despite a range of conditions and paper types. Drying energy consumption values of about $3.5 \mathrm{MJ} / \mathrm{kg}$ corresponded to drying efficiencies of up to $80 \%$, with better and more consistent performance at the high end of the temperature range considered, i.e. $70^{\circ} \mathrm{C}$. Measured drying rates compared well with predicted values calculated from the drier plate temperature and ambient conditions.

As a prototype for a solar drying system, the performance was satisfactory, with the result that the project has moved ahead to larger-scale on-site testing. Larger-scale driers will be of similar design, with the solar collector array and backup heat sized to provide water at an average temperature of $70^{\circ} \mathrm{C}$. The drying rate calculations will allow for the design of larger-scale driers based on typical weather conditions and modeled solar collector output.

\section{REFERENCES}

1. Subramanian, T. N. \& Kumar, A., 1995, "Development of the Indian handmade paper industry a case study," at www.devalt.org/newsletter/oct95/of_1.htm

2. Noble, N., 2002, "Small-scale paper-making," at http://practicalaction.org/paper-making

3. Tang, R., Gao, W., Yu, Y. \& Chen, H., 2009, "Optimal tilt-angles of all-glass evacuated tube solar collectors," Energy, 34, 1387-1395.

4. Duffie, J. A. \& Beckman, W. A., 1991, Solar Engineering of Thermal Processes, Wiley InterScience.

5. Morrison, G. \& Budihardjo, I., 2009, "Performance of water-in-glass evacuated tube solar water heaters," Sol. Energy, 83, 49-56.

6. Ek, M., Gellerstedt, G. \& Henriksson, G., 2009, Pulp and Paper Chemistry and Technology, Walter de Gruyter.

7. Churchill, S. W. \& Chu, H. H. S., 1975, "Correlating equations for laminar and turbulent free convection from a vertical plate," Int. J. Heat Mass Transf., 18, 1323-1329. 